\title{
Novel Chloroflexi genomes from the deepest ocean reveal metabolic strategies for the adaptation to deep-sea habitats
}

\author{
Rulong Liu ( $\sim$ rlliu@shou.edu.cn ) \\ Shanghai Ocean University https://orcid.org/0000-0001-5198-0422 \\ Xing Wei \\ Shanghai Ocean University \\ Li Wang \\ Shanghai Ocean University \\ Junwei Cao \\ Shanghai Ocean University \\ Weizhi Song \\ University of New South Wales \\ Jiaxin Wu \\ Shanghai Ocean University \\ Torsten Thomas \\ University of New South Wales \\ Tao Jin \\ BGI-Shenzhen: BGI Group \\ Wenxia Wei \\ Shanghai Ocean University \\ Yuli Wei \\ Shanghai Ocean University \\ Haofeng Zhai \\ Shanghai Ocean University \\ Cheng Yao \\ Shanghai Ocean University \\ Ziyi Shen \\ Shanghai Ocean University \\ Jiasong Fang \\ Shanghai Ocean University
}

Research 
Keywords: Chloroflexi, metabolic potential, persistent organic pollutant, PAH, PCB, dehalogenation, feast and famine, deep-sea, hadal trenches

Posted Date: March 1st, 2021

DOl: https://doi.org/10.21203/rs.3.rs-254541/v1

License: (c) (1) This work is licensed under a Creative Commons Attribution 4.0 International License. Read Full License 


\section{Abstract}

\section{Background:}

The deep-sea harbors the majority of the microbial biomass on Earth, and is a key site for organic matter (OM) remineralization and storage in the biosphere. Microbial metabolisms in the deep ocean are greatly controlled by the generally depleted but periodically fluctuating supply of OM. Currently, little is known about metabolic potentials of dominant deep-sea microbes to cope with the variable OM inputs, especially for those living in the hadal trenches - the deepest part of the ocean.

\section{Results:}

In this study, we report the first extensive examination of the metabolic potentials of hadal sediment Chloroflexi, a dominant phylum in hadal trenches and the global deep ocean. Sixty-two metagenomeassembled-genomes (MAGs) were reconstructed from nine metagenomic datasets derived from sediments of the Mariana Trench. These MAGs represent six novel species, four novel genera, one novel family and one novel order within the classes Anaerolinea and Dehalococcoidia. Fragment recruitment showed that these MAGs are globally distributed in deep-sea waters and surface sediments, and transcriptomic analysis indicated their in-situ activities. Metabolic reconstruction showed that hadal Chloroflexi mainly have a heterotrophic lifestyle, with the potential to degrade a wide range of organic carbon, sulfur and halogenated compounds. Our results reveal for the first time that hadal Chloroflexi harbor pathways for the complete hydrolytic or oxidative degradation of various recalcitrant $\mathrm{OM}$, including aromatic compounds (e.g. benzoate), polyaromatic hydrocarbons (e.g. fluorene), polychlorobiphenyl (e.g. 4-chlorobiphenyl) and organochlorine compounds (e.g. chloroalkanes, chlorocyclohexane). Moreover, these organisms show the potential to synthesize energy storage compounds (e.g. trehalose), and have regulatory modules to respond to changes in nutrient conditions. These metabolic traits lead us to postulate that the Chloroflexi may follow a "feast and famine" metabolic strategy, which allows them to efficiently consume labile $\mathrm{OM}$ and store the energy under rich $\mathrm{OM}$ conditions, and to survive under $\mathrm{OM}$ limitations by utilizing stored energy and degrading recalcitrant $\mathrm{OM}$.

\section{Conclusion:}

This study expands the knowledge on metabolic processes in deep-ocean Chlorolfexi, and highlights their significance in deep-sea carbon, sulfur and halogen cycles. The metabolic plasticity likely provides Chloroflexi with advantages for the survival under variable and heterogenic OM inputs in the deep ocean.

\section{Introduction}

The deep-sea harbors around $75 \%$ of the prokaryotic biomass and more than half of the prokaryotic production of the global ocean, and it is a key site for organic matter (OM) remineralization and storage 
in the biosphere [1]. An estimated $1-40 \%$ of the photosynthetically fixed carbon in the upper water reach the deep-sea [2], which is generally considered oligotrophic in nature [2,3]. The flux of nutrient varies in intensity and frequency over temporal and spatial scales [4-6], and mass input of particles from surface algal blooms may lead to periodic increases on quantity and bioavailability of $\mathrm{OM}$ in the deep ocean $[3$, 7]. Deep-sea microorganisms therefore have to employ special metabolic strategies to cope with the variable $\mathrm{OM}$ conditions to ensure their survival and functioning $[3,7]$.

Bacteria of the phylum Chloroflexi are dominant members of microbial communities in the global deep ocean $[8,9]$. For example, the SAR202 clade of the Chloroflexi on average accounts for $>10 \%$, and in some cases up to $40 \%$ of the total prokaryotic community in meso- and bathypelagic water of the Atlantic and Pacific oceans [8, 10-12]. Chloroflexi have also been shown to account for 25.5-41.3\% of total $16 \mathrm{~S}$ rRNA gene sequences in global marine sediments $[9,13,14]$. Currently, the knowledge on the metabolism of deep-sea Chloroflexi mainly relies on metagenomic or single-cell genomic analysis, due to the lacking of cultivated representatives for dominant deep-sea lineages [15-17]. These studies revealed that Chloroflexi from deep-sea waters harbor genes involved in organosulfur compounds degradation $[8,15]$, sulfite oxidation $[8,15]$, and the metabolisms of recalcitrant compounds such as cyclic alkanes and aromatic compounds [15-17]. The analysis of deep-sea Chloroflexi from anoxic subseafloor sediments suggest these bacteria have potential for reductive respiration of organohalogen compounds, and for the fermentation of $\mathrm{OM}$ combined with $\mathrm{CO}_{2}$ fixation via the Wood-Ljungdahl pathway $[9,18]$. These findings suggest that the Chloroflexi play important roles in biogeochemical cycles of the deep ocean. However, existing studies only covered a few seawater or anoxic subseafloor sites [8,9,15-18]. Given the high heterogeneity of the deep-sea habitats [3] and great phylogenetic and functional diversity of Chloroflexi bacteria $[9,17]$, the current understanding of the metabolisms of deep-sea Chloroflexi is therefore likely incomplete, and their genomic basis and metabolic strategies to adapt to fluctuations of OM supply (e.g. $\mathrm{OM}$ with different recalcitrancy) in the deep ocean are unclear.

The hadal trenches, which are formed by the subduction of tectonic plates, are the deepest part of the ocean [19]. Multiple sources of OM inputs combined with frequent OM remobilization due to special topographies, tectonic activities and intra-trench currents, lead to a higher heterogeneity and fluctuation of OM than in other deep-sea habitats [19-22]. However, despite the complex OM supply and extreme environmental conditions, such as high pressure, active microbial carbon turnover in hadal sediments has been frequently reported, making the hadal trenches "hot spots" of OM remineralization in the deep ocean [23-25]. Recently, Chloroflexi have been identified as one of the dominant taxa in seawater and sediment of the hadal trenches [15, 26, 27], and were found to primarily belonged to novel lineages [27]. In addition, hadal Chloroflexi were not only numerically dominant, but also highly transcribed in both hadal seawater and sediments (accounting for up to $36.2 \%$ of transcribed prokaryotic 16S rRNA sequences), suggesting a high in-situ activity $[15,27]$. Co-occurrence network analysis further revealed that Chloroflexi lineages are important in mediating the interactive network within hadal microbial communities [26, 27]. To date, only three studies reported the metabolism of hadal Chloroflexi based on 13 MAG/SAGs recovered from seawaters $[15,17,28]$. These bacteria were shown to encode enzymes to metabolize chitin, dimethyl 
sulfoxide, aromatic compounds (e.g. phthalate) and osmolytes [15, 28]. The studies shed light on the lifestyles of hadal Chloroflexi, but limited number of investigated genomes restricted the findings primarily to the SAR202 group II and III [15, 28]. The metabolic potentials of other dominant and novel lineages of Chloroflexiliving in the hadal zone are thus largely unknown.

In this study, we employed a metagenomic approach to fill the knowledge gap on metabolism of Chloroflexi that are living in surface sediments of the hadal zone. We obtained unique samples from the deepest point of the ocean, the Challenger Deep of the Mariana Trench. The retrieved MAGs were found to belong to novel lineages of Chloroflexi, representing major and widely distributed members of the hadal sedimentary microorganisms. The recovered Chloroflexi showed the capabilities to degrade a wide range of OM with different levels of recalcitrance. Our analysis also revealed for the first time the presence of hydrolytic and oxidative pathways for the complete degradation of various anthropogenic or natural polyaromatic hydrocarbons (PAHs), polychlorobiphenyl (PCBs), and halogenated organic compounds in deep-sea Chloroflexi. Potential metabolic strategies to respond to fluctuation and heterogeneity of OM in the hadal trenches are being proposed based on the metabolic reconstruction.

\section{Results And Discussion}

\section{Composition and activity of Chloroflexi in sediments of the Challenger Deep}

In this study, 16S rRNA genes and their transcripts were sequenced for samples from nine different depths of a sediment core retrieved from the Challenger Deep of the Mariana Trench. The results showed that Chloroflexi accounted on average for $20.9 \%$ and $19.1 \%$ of the total sequences for the bulk (i.e. $16 \mathrm{~S}$ rRNA gene) and potentially active (i.e. 16S rRNA) bacterial communities, respectively (Fig. 1). The distribution of the bulk Chloroflexi population was relatively stable and varied between $18.6-24.6 \%$ of total rRNA gene sequences in the upper $9 \mathrm{~cm}$ (Fig. 1). In contrast, the proportion of the transcribed Chloroflexi 16S rRNA sequences varied greatly with depth. Chloroflexi transcripts showed the highest proportion at $4-7 \mathrm{~cm}$ below seafloor, accounting for up to $40.6 \%$ of the total $16 \mathrm{~S}$ rRNA sequences (Fig. 1). The bulk and potentially active Chloroflexi populations were mainly composed of members from classes Anaerolineae, Dehalococcoidia, Chloroflexia, JG-KF-CM66 and KD4-96, among which Anaerolineae, Dehalococcoidia and JG-KF-CM66 were the most dominant ones (Fig. 1). These results are similar to previous studies on the microbial composition of hadal trench sediments [26, 27], indicating their general significance in maintaining the structure and functions of the hadal biosphere.

\section{MAG reconstruction, genome description and phylogenomic analysis}

A total of 62 Chloroflexi MAGs with completeness $>50 \%$ and contamination $<5 \%$ were reconstructed from the nine metagenomes covering different sediment layers (Additional file 1: Table S1). These MAGs were further dereplicated at $99 \%$ average nucleotide identity (ANI) to yield 17 representatives with an average completeness of $68.56 \%$ and contamination ranged from $0.00-3.64 \%$ (Table 1 and Additional file 1: Table S1). The genome sizes were estimated to range between 1.85-3.90 Mbp, and GC contents were between 58.64 and $69.45 \%$ (Table 1). Only fifteen genomes of Chloroflexi have previously been reported 
from the hadal zone (deeper than $6000 \mathrm{~m}$ ), and 13 of them were from seawater [15, 17, 28]. Only 2 Chloroflexi MAGs (GCA_004356475.1 and GCA_004356815.1) were found in the NCBI database to be recovered from hadal sediments, but they lacked any interpretation regarding their metabolism.

Table 1

Summary of the 17 representative MAGs retrieved from sediments of the Challenger Deep.

\begin{tabular}{|lllllll|}
\hline MAGs & $\begin{array}{l}\text { Completeness } \\
\text { (\%) }\end{array}$ & $\begin{array}{l}\text { Contamination } \\
(\%)\end{array}$ & $\begin{array}{l}\text { Contig } \\
\text { no. }\end{array}$ & GC\% & $\begin{array}{l}\text { CDS } \\
\text { no. }\end{array}$ & $\begin{array}{l}\text { Estimated genome size } \\
\text { (Mbp) }\end{array}$ \\
\hline MT1_49* & 60.51 & 3.08 & 400 & 62.83 & 2008 & 3.18 \\
\hline MT1_55 & 73.57 & 0.00 & 386 & 59.26 & 1683 & 2.33 \\
\hline MT1_63 & 56.40 & 2.97 & 296 & 59.82 & 1319 & 2.46 \\
\hline MT1_74 & 51.38 & 0.61 & 255 & 65.29 & 1016 & 1.98 \\
\hline MT2_3 & 85.70 & 0.00 & 472 & 59.61 & 3150 & 3.90 \\
\hline MT2_13 & 92.99 & 0.00 & 275 & 58.79 & 2237 & 2.74 \\
\hline MT2_40 & 52.07 & 2.20 & 253 & 69.45 & 1108 & 2.07 \\
\hline MT4_14 & 86.30 & 1.98 & 408 & 60.36 & 2572 & 3.05 \\
\hline MT4_27 & 89.96 & 0.31 & 215 & 65.69 & 1934 & 2.05 \\
\hline MT4_29 & 54.89 & 2.18 & 365 & 62.58 & 1770 & 3.09 \\
\hline MT5_40 & 66.01 & 0.20 & 359 & 58.76 & 1610 & 2.61 \\
\hline MT5_44 & 67.62 & 1.19 & 314 & 65.58 & 1512 & 2.29 \\
\hline MT6_13 & 84.77 & 0.11 & 425 & 60.34 & 2430 & 2.99 \\
\hline MT6_15 & 87.27 & 3.64 & 168 & 58.64 & 2397 & 2.85 \\
\hline MT6_44 & 51.99 & 0.00 & 486 & 59.57 & 1031 & 1.85 \\
\hline MT8_34 & 52.62 & 0.00 & 467 & 59.67 & 1199 & 2.16 \\
\hline MT9_49 & 51.53 & 2.38 & 257 & 69.22 & 1189 & 2.16 \\
\hline *, MAGs were named using “Site +layer + genome number”, for example MT1_49 means the 49th \\
genome from sediment of 1 cm below seafloor from the Mariana Trench.
\end{tabular}

Phylogenomic analysis showed that the MAGs belonged to the classes Anaerolinea, Dehalococcoidia and SAR202 (previously classified as a class) (Fig. 2, Additional file 1: Table S2, Additional file 2: Fig. S1). Taxonomic classification of the MAGs using GTDB-Tk toolkits [29] revealed that the MAGs represent six novel species (MT1_49, MT2_13, MT5_40, MT1_63, MT1_55, MT4_14) and four novel genera (MT4_27, MT1_74, MT9_49, MT2_3) in the orders SM23-28-2, SAR202 (former SAR202 group II), UBA2963 (former SAR202 group VII), UBA1151(former SAR202 group I) and UBA3495 (former SAR202 group III) of the 
class Dehalococcoidia (Fig. 2, Additional file 1: Table S3 and Additional file 2: Fig. S1). In addition, MT5_44 represent a novel order in the class Dehalococcoidia, and MT6_15 represent a novel family in the order Anaerolineales of the class Anaerolinea (Fig. 2 and Additional file 1: Table S3). The novelty of the MAGs was also assessed based on the average nucleotide identity (ANI) by comparing them to their closest genomes from the NCBI and GTDB databases (Additional file 1: Table S3). Sixteen MAGs (except MT6_15) shared ANI values lower than $95 \%$ with their closest genomes from both databases (Additional file 1: Table S3). MT6_15 showed ANI value of $96.8 \%$ with a genome from surface sediments of the Mariana Trench (GCA_004356475.1), which was not included in GTDB database, possibly due to low completeness. Therefore, MT6_15 and GCA_004356475.1 together represent a new family of the Anaerolineae under GTDB classification (Fig. 2 and Additional file 1: Table S3).

Six MAGs including MT6_15, MT4_27, MT2_13, MT2_3, MT6_13 and MT4_14, showed completeness of > $80 \%$ and contaminations lower than $3.6 \%$ (Table 1 ), and are qualified as type materials according to the criteria defined recently for taxonomy of uncultivated prokaryotes [30, 31]. Taxonomy names for these MAGs were proposed and can be found in Additional file 3.

\section{Distribution of the reconstructed MAGs in hadal sediments and other ecosystems}

Five MAGs (MT4_27, MT2_13, MT2_3, MT6_13, and MT4_14) were found to contain partial 16S rRNA gene that matched with OTUs from 16S rRNA or 16S rRNA gene libraries constructed in this study (Fig. 3B). These OTUs were mainly distributed in the upper $8 \mathrm{~cm}$ of the sediment, and together accounted for $4.0-9.9 \%$ and $3.9-14.8 \%$ of Chloroflexi sequences in the 16S rRNA gene and 16S rRNA libraries, respectively (Fig. 3B). Recruitment of shotgun sequencing reads showed that the 17 recovered MAGs were present in all depths $(0-10 \mathrm{~cm}$ below seafloor) of the sediments, and MT6_44, MT1_74, MT8_32, MT9_49 and MT2_40 were the most abundant ones (Fig. 3C). The five MAGs with 16S rRNA gene showed the lowest recruitment values (Fig. $3 \mathrm{C}$ ). It is therefore reasonable to assume that the 12 MAGs without 16S rRNA genes might be more abundant in the bulk and active bacterial communities than the five MAGs with 16S rRNA gene (Fig. 3B). These results suggest that the recovered MAGs represent major members of Chloroflexi in the hadal sediment of the Mariana Trench.

The global distribution of recovered MAGs was evaluated by read recruitments against 58 metagenomes derived from different natural habitats, including seawater and surface sediments from different depths of the open ocean, sediments of mud volcanos, deep-sea oil spilling sites, deep subseafloors, coastal regions, rivers and salt-lakes, as well as soils (Fig. 3A,3D and Additional file 1: Table S4). All of the 17 MAGs showed the highest recruitment values in surface sediments of the Mariana Trench, including the nine samples analyzed in this study (water depth of $10853 \mathrm{~m}$ ) (Fig. 3C) and two samples with water depths of $7942 \mathrm{~m}$ and 5835m (Fig. 3D and Additional file 1: Table S4), which likely reflect the biogeographic distributions due to local environmental selection [8]. The majority of the MAGs (except order SM23-28-2) have recruited reads from metagenomes derived from sediments and seawaters of worldwide deep oceans (Fig. 3D and Additional file 1: Table S4), and none of the MAGs was present in seawater or sediments from shallow habitats, including epi-pelagic zone of the open ocean, coastal 
regions, and river, salt-lake or soil (Fig. 3D). The results suggest that majority of the recovered MAGs are widespread in deep seawater and surface sediment of the deep oceans.

However, MAGs from different orders showed apparent preferences in their distributions in different deepsea habitats. MAGs from the order UBA3495 (former SAR202 group III) showed high recruitment values in both deep seawater and sediment metagenomes (Fig. 3D). The SAR202 group III has been previously shown to be one of the most dominant Chloroflexi in the water column of the global deep ocean $[17,28]$, and our result highlights the significance of these bacteria in both pelagic and sedimentary habitats of the deep ocean. Expansion of paralogous enzymes, such as flavin-dependent monooxygenases, in SAR202 group III has been suggested to be important for their adaptation in different deep-sea habitats, by diversifying the range of organic molecules that the cells can utilize $[16,17]$. In contrast to UBA3495, MAGs from the orders Anaerolineales, SAR202 (former SAR202 group II), UBA2963 (former SAR202 group VII), UBA1151 (former SAR202 group I) and the novel order (MT5_44) showed higher recruit values in metagenomes from deep-sea sediments compared to those from seawater, suggesting their preferential distribution in deep sea sediment habitats. Interesting, the MAGs of the order SM23-28-2 (particularly MT1_74) only matched with the reads from sediment metagenomes of the Mariana Trench (Fig. 3D), indicating a potential endemism for the Mariana Trench, which might be a result of long-term adaptation to the special geographic, physical and chemical conditions of the Mariana Trench, such as extreme depth, tectonic activity, geographic isolation and nutrient inputs [19, 32].

\section{Metabolic overview: a heterotrophic lifestyle with the capability for degrading a wide range of organic carbon and sulfur compounds}

Genome annotation of the recovered MAGs revealed their potentials for organo-heterotrophic metabolisms and utilization of a wide range of OM (Fig. 4). Gene sets encoding for complete/near complete pathways or key enzymes in the central carbohydrate metabolism, including glycolysis, tricarboxylic acid cycle (TCA cycle), pentose phosphate pathway, and $\beta$-oxidation of fatty acids, were present in all MAGs with genome completeness $>80 \%$ (Fig. 4 and Additional file 1: Table S5). These pathways allow the degradation/transformation of simple sugars (e.g. glucose), fatty acids, as well as amino acids. On top of this, genes encoding extracellular cellulases (MT4_29, MT2_13, MT1_55), chitinases (occurred in most MAGs) and polygalacturonases (MT2_13) as well as ABC type transporters for polysaccharides were present in the MAGs (Fig. 4 and Additional file 1: Table S6), suggesting the potential to degrade complex polysaccharides, such as cellulose, chitin or pectin. In addition, different types of peptidases as well as $A B C$ type transporters for amino acids, dipeptides and oligopeptides were found to be present in the Chloroflexi MAGs, indicating their potential to degrade protein detritus (Fig. 4 and Additional file 1: Table S6).

The hadal sediment Chloroflexi MAGs also had the potential capability to degrade various organosulfur compounds (Fig. 4). Alkanesulfonate monooxygenase present in 13 of the 17 MAGs recovered (Fig. 5 and Additional file 1: Table S6) and this enzyme cleaves carbon-sulfur bonds in a wide range of sulfonated alkanes to produce sulfite and aldehyde [33], with the latter being able to be oxidized to fatty acid by an 
alkanal monooxygenase, whose coding gene was also present in 13 of the 17 the MAGs (Fig. 5 and Additional file 1: Table S6). In addition, genes coding for homologs of enzymes involved in dimethylsulfide (DMS) (i.e. DMS monooxygenase and DMS dehydrogenase) and methanesulfonate metabolisms (i.e. methanesulfonate monooxygenase) were found in the MAGs (Fig. 4 and Fig. 5), and genes encoding the ABC-type sulfonate transporters were identified (Fig. 4 and Additional file 1: Table S6). The results suggested the potential of hadal sediment Anaerolineae and Dehalococcoidia to utilize multiple organic sulfur compounds as energy, carbon and sulfur sources, a finding that was similar with previous reports on SAR202 clade (primarily SAR202 group III) from deep seawater $[8,28]$.

\section{Pathways for the degradation of phthalate, benzoate, polyaromatic hydrocarbons (PAHs) and polychlorobiphenyl (PCB) compounds}

The Chloroflexi MAGs harbor pathways for the degradation of benzoate and phthalate (Fig. 4 and Fig. 5). Eight MAGs from the orders SAR202, UBA2963 and UBA3495 contained complete or near complete gene clusters encoding six enzymes for the degradation of benzoate to pyruvate or oxaloacetate (Fig. 5 , Additional file 1: Table S6 and Additional file 2: Fig. S2). Eight MAGs from the orders UBA2963 and UBA3495 contained genes encoding complete or near complete pathways for degradation of phthalate to 4-carboxy-2-hydroxymuconate semialdehyde (HCMS) (Fig. 5, Additional file 1: Table S6 and Additional file 2: Fig. S3), and the four MAGs from UBA2963 contained genes encoding enzymes that can further degrade HCMS to pyruvate (Fig. 5, Additional file 1: Table S6 and Additional file 2: Fig. S3). As benzoate and phthalate are common intermediates in the degradation of many aromatic compounds, we hypothesized that the recovered MAGs might also be able to degrade substrates with more complex structures. Indeed, complete or near complete pathways for the degradation of polyaromatic hydrocarbons (e.g. fluorene) and polychlorobiphenyls (PCBs, e.g. biphenyl and 4-chlorobiphenyl) were found (Fig. 5). Six MAGs from the orders UBA2963 and UBA3495 harbor near complete pathways for the transformation of fluorene to phthalate (Fig. 5, Fig. 6 and Additional file 1: Table S6). Nine MAGs from the orders UBA2963 and UBA3495 harbor complete or near complete pathways for the transformation of biphenyl to benzoate (Fig. 5, Additional file 1: Table 66 and Additional file 2: Fig.S4). In addition, the nine MAGs from the orders UBA2963 and UBA3495 also contain complete or near complete pathways for the degradation of 4-chlorobiphenyl to 4-hydroxy-benzoyl-CoA (Fig. 5, Fig. 6 and Additional file 1: Table S6), which can be further metabolized via benzoate degradation pathway (Fig. 6).

As labile $\mathrm{OM}$ is usually readily utilized by microorganisms in the upper water layers, the remaining $\mathrm{OM}$ in the deep ocean often includes a variety of structurally complex compounds, such as aromatic compounds [34]. Partial pathways of phthalate degradation (phthalate to protocatechuate), and some enzymes involved in the degradation of benzoate (e.g. catechol 2,3-dioxygeenase) or other aromatic compounds have been reported in SAR202 MAGs/SAGs from seawater of hadal trenches and other deepsea environments $[15-17,28]$, and related genes were highly transcribed in in-situ $[15,28]$. This study advances the existing knowledge by reporting the pathways for the complete degradation of phthalate and benzoate to $\mathrm{CO}_{2}$ by hadal sediment Chloroflexi, and is the first time to show that deep-sea Chloroflexi harbor pathways to completely degrade fluorene, biphenyl and 4- chlorobiphenyl. 


\section{Pathways for hydrolytic degradation of halogenated organic compounds}

In this study, we further discovered in hadal sediment Chloroflexi the prevalence of genes encoding haloalkane dehalogenase, haloacetate dehalogenase, and 2-haloacid dehalogenase (Fig. 5 and Additional file 1: Table S6), which catabolize hydrolytic dehalogenation, replacing the halogen molecules in organohalides with hydroxyl groups [35]. These enzymes have a broad-specificity and participate in the degradation of multiple halogenated OM [35]. Complete or near complete pathways for the hydrolytic and oxidative degradation of several chloroalkenes and chlorocyclohexane compounds were further found (Fig. 4, Fig. 5). Nine MAGs from the orders Anaerolineales, SM23-28-2, UBA1151 and UBA3495 harbor genes encoding the complete or near complete pathways for the degradation of 1,2-dichloroethane to glycolate (Fig. 6 and Additional file 1: Table S6), which can either be further transformed and enter the TCA cycle or be utilized for vitamin B6 biosynthesis. The same pathway also catabolizes the degradation of trans-dichloropropene and cis-dichloropropene to trans-3- and cis-3-chloroacrylic acid, respectively (Fig. 5, Additional file 1: Table S6 and Additional file 2: Fig. S5). In addition, a pathway for the complete degradation of $y$-hexachlorocyclohexane to succinyl-CoA (an intermediate in TCA cycle) was reconstructed in the Chloroflexi MAGs (Fig. 5). The entire pathway involves 11 enzymes (Fig. 6 and Additional file 1: Table S6), and complete or near complete sets of genes encoding these enzymes are present in three MAGs from the order UBA3495 (Fig. 5). Nigh MAGs from orders Anaerolineales, SM23-282, SAR202, UBA1151, UBA3495 and the novel order (MT5_44) also encode for the majority of enzymes for Y-hexachlorocyclohexane degradation, but with 2-6 enzymes missing (Fig. 5 and Additional file 1: Table S6).

Currently, deep-sea Chloroflexi have mainly been implied in reductive dehalogenation $[9,36,37]$, a strictly anaerobic process which utilizes halogenated organic compounds as electron acceptor to oxidize hydrogen (or formate) [38]. In contrast, the hydrolytic and oxidative degradation of organohalides are aerobic processes [35]. The genes coding for haloalkane and haloacetate dehalogenases have been previously reported to occur in Chloroflexi genomes from oxic abyssal sediments [39] and our study revealed for the first time the complete or near complete pathways for hydrolytic and oxidative degradation of multiple types of organohalides in hadal trench Chloroflexi (Fig. 4 and Fig. 5). The MAGs were recovered from surface sediments of the Challenger Deep at depth of 0-10 cm below seafloor, which are well oxygenated as revealed by in-situ oxygen measurement conducted at the same site [25]. In addition, reads recruitment showed that the majority of the MAGs were widely distributed in surface sediment and seawaters in the deep ocean (Fig. 3), highlighting the significance of Chloroflexi in carbon and halogen cycling in oxygenic habitats of the deep ocean.

\section{Microbial degradation of persistent organic pollutants (POPs) in the deepest ocean}

The metabolic reconstruction of the recovered MAGs in this study reveals the potential of hadal sediment Chloroflexi for the complete degradation of several types of recalcitrant organic compounds, including PAHs (i.e. fluorene), PCBs (e.g. 4-chlorobiphenyl), haloalkanes (e.g. 1,2-sichloroethane and 1,3dichloropropene), and chlorocyclohexane ( $\mathrm{Y}$-hexachlorocyclohexane) (Fig. 5 and Additional file 1: Table 
S6). These findings have important implications for the deep ocean ecosystems in general, and the hadal trench systems in particular. Many of these compounds are listed as persistent organic pollutants (POPs) by the Stockholm Convention [40] and their presence and accumulation in deep-sea organisms and environments have been widely reported [41, 42]. Recent studies have further revealed that PCBs, microplastics, heavy metals and halogenated organic pollutants have even accumulated in the deepest trenches of the ocean [43-46], suggesting that the anthropogenic pollutants can be an important part of the OM pool in the hadal trenches. Many types of PAHs and POPs-like compounds can however also be naturally produced via biotic (e.g. biosynthesis via halogenase or haloperoxidase) and abiotic processes (e.g. peroxidative mechanisms, photochemical reactions, volcanic activities) [36, 47, 48], and can be enriched in the deep ocean via the "biological pump" [49]. The capability to metabolize these recalcitrant OM would likely provide Chloroflexi bacteria with survival advantages in nutrient/energy limited habitats, which might be one of the reasons for their dominance in the sediments of the hadal trenches as observed in this (Fig. 3) and previous studies [26, 27]. In addition, the degradation of recalcitrant OM by Chloroflexi may produce semi-labile intermediates serving as substrates for other taxa in the microbial community [38], which might be one of the reasons for previous observations that Chloroflexi lineages play important roles in interactive networks of microbial community in the sediment of the hadal trenches [27].

\section{A potentially "feast and famine" metabolic strategy in response to fluctuating supply of OM}

Deep-sea benthic communities experience feast-or-famine conditions due to the periodical and spatial variations of particles input in a generally energy-depleted environment [7]. Deep-sea microbial communities have been shown to respond rapidly to nutrient input, even after long periods of starvation [50]. However, little is known about the genomic basis and potential metabolic strategies of deep-sea microorganisms for such a lifestyle. Our results showed that the hadal Chloroflexi exhibit capabilities of degrading a wide range of organic carbon, sulfur and halogen compounds (Fig. 4 and Fig. 5), including not only labile OM, but also many types of recalcitrant organic compounds (Fig.5 and Fig. 6). In addition, the MAGs harbor genes encoding key enzymes for the formation of at least one type of intracellular energy storage compound (Fig. 5 and Additional file 1: Table S6), including alpha, alpha-trehalose synthase, trehalose-6-phosphate synthase and trehalose-phosphate-phosphatase for the formation of trehalose [51], glycogen synthase for the biosynthesis of glycogen [52], polyphosphate kinase for the formation of polyphosphate inclusions [53], or sulfide-quinone reductase, sulfite reductase and sulfide dehydrogenase for the formation of sulfur globules [52]. Such features are consistent with a "feast and famine" metabolic strategy (Fig. 7). During the "feast" condition, such as an input of particulate OM due to diatom bloom in the surface water [7], the bacteria might preferentially uptake and consume labile OM, and excess energy, carbon and other elements can be stored as intracellular inclusions (Fig. 7). During "famine" condition (i.e. nutrient depleted), the bacteria may enter the "famine" mode to acquire energy from stored inclusions, and/or from degrading the recalcitrant $\mathrm{OM}$ available in the surrounding environments (Fig. 7). 
In supporting of such a "feast and famine" lifestyle, the MAGs also harbor modules for the regulation of metabolism in response to changes of nutrient conditions (Fig. 5). The majority of the MAGs contained genes encoding pyruvate orthophosphate dikinase, PEP carboxylase, malate dehydrogenase, and malic enzyme (Fig. 5), which catalyze the inter-conversions between pyruvate, PEP, oxaloacetate and malate (Additional file 2: Fig. S6). These reactions interconnect central carbon metabolic pathways (e.g. the TCA cycle and biosynthesis) and are responsible for regulating carbon fluxes among catabolism, anabolism and energy supply according to the physiology conditions of the cell (Additional file 2: Fig. S6) [54]. In addition, all of the recovered MAGs harbor the Irp gene (COG1522) encoding the leucine-responsive regulatory protein (LRP) (Fig. 5), which is one of the "feast and famine" regulatory proteins that can control the expression of more than $30 \%$ of bacterial genes in response to changes of nutrient levels [ 55 , 56]. The existence of these regulatory genes suggests the potential of the hadal Chloroflexi to rapidly change the metabolism and physiology under the feast or famine conditions.

\section{Conclusions}

This study provides an extensive exploration of the metabolic potential of novel and dominant Chloroflexi lineages from the hadal sediments of the Mariana Trench. The results demonstrated a high metabolic plasticity of the hadal sediment Chloroflexi, including the complete pathways for hydrolytic or oxidative degradation of recalcitrant OM such as PAHs, PCBs and organohalides. Our findings expand the current understanding on metabolic capabilities of deep-sea Chloroflexi, and highlight their significance on carbon, sulfur and halogen cycling in the deep ocean. The metabolic plasticity, the capability to form intracellular storage inclusions, as well as the regulatory modules to respond to nutrient conditions discovered in the MAGs support the notion that the hadal sediment Chloroflexi employ a "feast and famine" metabolic strategy. Such a metabolic strategy allows the bacteria to fulfill energy and nutrient requirement via degradation of different substrates according to the nutrient conditions, and regulate the cell activities (e.g. growth, motility) correspondingly, providing advantages for their adaptation to the variable $\mathrm{OM}$ conditions in the hadal trenches and other deep-sea habitats. This study therefore provides a new perspective on the metabolism and adaptation strategies of Chloroflexi in deep-sea environments.

\section{Material And Methods:}

\section{Site description and sampling}

Sediment samples were obtained from the Challenger Deep of the Mariana Trench (site MT, $11.4037^{\circ} \mathrm{N}$, $142.3630^{\circ} \mathrm{E}$, water depth of $10,853 \mathrm{~m}$ ) during the cruise from December 2016 to January 2017 by the MV Zhangjian. Samples were collected using a box corer attached to a Hadal Lander [25]. Details of the sampling procedure are given in Liu et al. [27]. After recovering on board, the sediment samples were immediately subsampled using sterile plastic corers and stored at $-80^{\circ} \mathrm{C}$ on board.

\section{Amplicon sequencing analysis on 16S rRNA and rRNA gene diversity}


Sediment cores were thawed on ice and were depth fractioned to $0-2,2-3,3-4,4-5,5-6,6-, 7-8,8-9$ and $9-10 \mathrm{~cm}$ subsamples. Total DNA and RNA were co-extracted from triplicate 1-g sediments of each depth fraction using the PowerSoil Total RNA Isolation Kit and DNA Elution Accessory Kit (MoBio Lab, United States) following the manufacturer's instructions. The RNA samples were treated with DNase I and cDNAs were synthesized using the GoScriptTM Reverse Transcription System (Promega, United States) with random primers. DNA and cDNA samples were amplified with a barcoded primer set 338F/806R targeting the V3-V4 hypervariable regions of bacteria [57]. Detailed procedure for DNA/RNA coextraction and PCR are given in Liu et al. [27]. PCR products from each sample were purified using an AxyPrep DNA Gel Extraction Kit (Axygen Biosciences, Union City, CA, United States) and quantified using QuantiFluorTM-ST (Promega, United States). Purified amplicons from different samples were pooled in equimolar ratio and subjected to paired-end sequencing $(2 \times 300)$ on an Illumina MiSeq platform (Illumina, San Diego, CA, United States) in Majorbio Bio-Pharm Technology Co. Ltd. (Shanghai, China). The procedure of the sequence processing was the same as Liu et al. [27]. Briefly, the raw reads were demultiplexed, quality-filtered and assembled, followed by the identification and removal of chimeric sequences. Operational taxonomic units (OTUs) were obtained using UPARSE (v. 7.1) at 97\% similarity cutoff, and their taxonomy was assigned by RDP Classifier against SILVA 16S rRNA database (SSU138) with a confidence threshold of $70 \%$.

\section{Metagenomic sequencing and genome reconstruction}

Total genomic DNA was extracted from 10-20 gram of sediments from each depth fraction, using the FastDNA® SPIN Kit for Soil (MP Biomedicals, USA). DNA fragment libraries were prepared by shearing genomic DNA from each sample and were then subjected to metagenomic sequencing in BGI group (Shenzhen, China) using BGIseq 500 platform, which generated $111 \mathrm{~Gb}$ of raw reads for the nine metagenomes (10.1-17.7 Gb for individual metagenome).

Metagenomic reads from each sample were quality filtered using Trimmomatic v. 0.38 [58] with parameters specified as "LEADING:30 TRAILING:30 CROP:90 HEADCROP:10 SLIDINGWINDOW:4:25 MINLEN:50", and were separately assembled with IDBA_UD v. 1.1 .3 (kmer range 50-80, step 15) [59]. The quality-filtered reads were mapped back to the assemblies using Bowtie2 (v. 2.3.4.1) [60], and coverage was determined according to the mapping results with the jgi_summarize_bam_contig_depths script [61]. Metagenome binning was conducted for assemblies longer than 2500 bp using MetaBAT v. 2.12.1 [61] and CONCOCT v. 1.0.0 [62] with default parameters, and were subsequently refined using Binning_refiner v. 1.2 [63]. Quality of the MAGs was assessed by CheckM v. 1.1.2 using the lineage_wf workflow [64], and only MAGs with completeness $>50 \%$ and contamination $<5 \%$ were kept for further analysis. Redundant bins were subsequently dereplicated using dRep v. 2.3.2 [65] at 99\% average nucleotide identity (ANI), and MAG with highest quality was selected from each cluster for downstream analysis. The genome size was estimated by dividing the size of the MAG by its estimated completeness.

\section{Phylogenomic analysis and taxonomic classification}


A phylogenomic tree was constructed for the MAGs and 1872 Chloroflexi genomes available from NCBI and JGI databases (downloaded in April, 2020), using the 43 universal single-copy genes (SCGs) used by CheckM [64]. Protein sequences of the SCGs were identified using HMMER v. 3.1b2 [66] with default parameters, individually aligned with MAFFT v. 7.467 [67] and then concatenated. Phylogenomic tree was constructed based on the alignment using FastTree2 v. 2.1.11 [68], with a JTT model, a gamma approximation and 100 bootstrap replicates.

The closest genomes of each MAG were determined based on their placements in the phylogenomic tree. A final maximum-likelihood phylogenomic tree was then constructed using the MAGs recovered in this study, their closest relatives, all Chloroflexi genomes previously reported from trenches, and representative genomes of all known classes of Chloroflexi, with Mycobacterium tuberculosis (GCA_000195955.2) as outgroup. The phylogenomic tree was visualized using iTOL [69]. Detailed taxonomic classification of the MAGs was determined using GTDB-Tk, which is based on the phylogenetically calibrated Genome Taxonomy Database (GTDB) [29]. The novelty of the MAGs was determined based on the classification provided by GTDB-Tk, and also considering the ANI values between each MAG and its closest relatives. FastANI v. 1.3 was used for ANI calculation and a MAG sharing less than $95 \%$ ANI to the closest genomes was considered as a novel species [70].

\section{Relative abundance estimation and global distribution}

To estimate relative abundance and distribution of recovered MAGs in the sampled hadal sediments, $16 \mathrm{~S}$ rRNA gene of the MAGs were predicted using barrnap v. 0.9 with default parameters (https://github.com/tseemann/barrnap), and searched with BLASTN [71] against the 16S rRNA and 16S rRNA gene libraries constructed in this study. Only the BLASTN hits with identity $>97 \%$, alignment length $>300 \mathrm{bp}$, and e-value $<1 \mathrm{e}^{-5}$ were considered, and the closest matched OTUs were selected. If multiple OTUs were identified as the closest matches for a MAG, the most abundant OTU was selected. The closest-match OTUs were then extracted and their relative abundance in the 16S rRNA and 16S rRNA gene libraries from different layers of the sediment were examined.

The distribution of MAGs in hadal sediments were also estimated via reads recruitment as described by Mehrshad et al. [8]. Briefly, rRNA gene sequences in MAGs were first masked to avoid bias in recruitment results. Recruitments were performed using BLASTN, and hits were filtered with a length cut-off of $50 \mathrm{bp}$, an identity cut-off of $95 \%$ and an e-value cut-off of $1 e^{-5}$ [8]. Qualified hits were used to compute the RPKG (reads recruited per kilobase of genome per gigabase of metagenome) values, which reflect a normalized abundance allowing the comparison across different genomes and metagenomes. Reads recruitment was also applied against 58 publicly available metagenomes derived from microbial communities in seawater and surface sediments from epi-, meso-, bathyl- and hadal zones of the open ocean, and those from sediments of mud volcano, deep-sea oil spilling sites, deep subseafloor, coastal regions, river and salt-lake, as well as two metagenomes from soil (Additional file 1: Table S4), to estimate the global distribution of recovered MAGs. 


\section{Gene annotation and metabolic reconstruction}

Coding sequences in the MAGs were predicted using Prodigal v. 2.6 .3 with default setting [72]. Functional annotation was performed by using BlastKOALA against the KEGG database with default parameters [73], by running similarity searches with BLASTP against the Cluster of Orthologous Groups (COG, December 2014 release) with an e-value cut-off of 0.001 [74], as well as by running PROKKA under the "metagenome" mode and with kingdom specified as "Bacteria" [75]. Carbohydrate active enzymes were identified using dbCAN 1.0 (default setting) against the CAZy database (version 07312019) [76]. Missing enzymes for pathways of interest were further searched by running tBLASTn against relevant reference sequences in the NCBI database. A tBLASTn hit with an e-value $\leq \mathrm{e}^{-5}$, sequence identity $\geq 30 \%$ and a percent alignment length $\geq 30 \%$ was considered as a potential homolog [77].

\section{Declarations}

\section{Acknowledgements}

The authors thank Prof. Weicheng Cui, Prof. Yunping Xu, Dr. Binbin Pan and their scientific and technological teams, as well as crews of the R/V Zhangjian for cruise organization, technological supporting, and assistance on sampling.

\section{Authors contributions}

$\mathrm{RL}$ and JF designed the work and supervised the entire procedures of experiment, data analysis and manuscript writing. XW, JW, TJ, WW, HZ, CY and ZS conducted experiments. WS, XW and LW conducted bioinformatic analysis. JC, TT and YW provided ideas for data analysis and interpretation. RL, XW, WS and JF wrote the manuscript. All authors provided comments and edited the manuscript.

\section{Funding}

This work was supported by the National Key R\&D Program of China (Grant No. 2018YFC0310600), the National Natural Science Foundation of China (Grant No. 91951210, 41773069, 41906134), the Shanghai Natural Science Foundation (20ZR1423700), and a R\&D project registered as ANP 21005-4, "PROBIODEEP - Survey of potential impacts caused by oil and gas exploration on deep-sea marine holobionts and selection of potential bioindicators and bioremediation processes for these ecosystems" sponsored by Shell Brasil under the ANP R\&D levy as "Compromisso de Investimentos com Pesquisa e Desenvolvimento".

\section{Availability of data and materials}

The sequences of 16S rRNA and 16S rRNA gene libraries, the metagenomic raw reads of the Mariana Trench sediments, as well as all metagenome assembled Chloroflexi genomes of this study are available in NCBI database and can be accessed under project ID PRJNA692099. 


\section{Ethics approval and consent to participate}

Ethics approval was not required for this study.

\section{Consent for publication}

Not applicable.

\section{Competing interests}

The authors declare no competing interests.

\section{References}

1. Arístegui J, Gasol JM, Duarte CM, Herndld GJ. Microbial oceanography of the dark ocean's pelagic realm. Limnol Oceanogr. 2009;54:1501-29.

2. Herndl GJ, Reinthaler T. Microbial control of the dark end of the biological pump. Nat Geosci. 2013;6:718-24.

3. Jørgensen BB, Boetius A. Feast and famine-microbial life in the deep-sea bed. Nat Rev Microbiol. 2007; 5:770-81.

4. Conte MH, Ralph N, Ross EH. Seasonal and interannual variability in deep ocean particle fluxes at the Oceanic Flux Program (OFP)/Bermuda Atlantic Time Series (BATS) site in the western sargasso sea near Bermuda. Deep Sea Res Part II Top Stud Oceanogr. 2001;48:1471-505.

5. Arístegui J, Montero MF. Temporal and spatial changes in plankton respiration and biomass in the Canary Islands region: the effect of mesoscale variability. J Mar Syst. 2005;54:65-82.

6. Smith KL Jr, Ruhl HA, Huffard CL, Messié M, Kahru M. Episodic organic carbon fluxes from surface ocean to abyssal depths during long-term monitoring in NE Pacific. Proc Natl Acad Sci U S A. 2018;115:12235-40.

7. Grabowski E, Letelier RM, Laws EA, Karl DM. Coupling carbon and energy fluxes in the North Pacific Subtropical Gyre. Nat Commun. 2019;10:1895.

8. Mehrshad M, Rodriguez-Valera F, Amoozegar MA, López-García P, Ghai R. The enigmatic SAR202 cluster up close: shedding light on a globally distributed dark ocean lineage involved in sulfur cycling. ISME J. 2018;12:655-68.

9. Fincker M, Huber JA, Orphan VJ, Rappé MS, Teske A, Spormann AM. Metabolic strategies of marine subseafloor Chloroflexi inferred from genome reconstructions. Environ Microbiol. 2020;22:3188-204.

10. Morris RM, Rappé MS, Urbach E, Connon SA, Rappe MS, Giovannoni SJ. Prevalence of the Chloroflexi-related SAR202 bacterioplankton cluster throughout the mesopelagic zone and deep ocean. Appl Environ Microbiol. 2004;70:2836-42.

11. Schattenhofer M, Fuchs BM, Amann R, Zubkov MV, Tarran GA, Pernthaler J. Latitudinal distribution of prokaryotic pico- plankton populations in the Atlantic Ocean. Environ Microbiol. 2009;11:2078-93. 
12. Varela MM, Van Aken HM, Herndl GJ. Abundance and activity of chloroflexi-type SAR202 bacterioplankton in the meso- and bathypelagic waters of the (sub)tropical Atlantic. Environ Microbiol. 2008;10:1903-11.

13. Parkes RJ, Cragg B, Roussel E, Webster G, Weightman A, Sass H. A review of prokaryotic populations and processes in sub-seafloor sediments, including biosphere:geosphere interactions. Mar Geol. 2014;352:409-25.

14. Hoshino T, Doi H, Uramoto Gl, Wörmer L, Adhikari RR, Xiao N, et al. Global diversity of microbial communities in marine sediment. Proc Natl Acad Sci U S A. 2020;117:27587-97.

15. Gao ZM, Huang JM, Cui GJ, Li WL, Li J, Wei ZF, et al. In situ meta-omic insights into the community compositions and ecological roles of hadal microbes in the Mariana Trench. Environ Microbiol. 2019;21:4092-108.

16. Landry Z, Swan BK, Herndl GJ, Stepanauskas R, Giovannoni SJ. SAR202 Genomes from the Dark Ocean Predict Pathways for the Oxidation of Recalcitrant Dissolved Organic Matter. mBio. 2017;8:e00413-17.

17. Saw JHW, Nunoura T, Hirai M, Takaki Y, Parsons R, Michelsen M, et al. Pangenomics Analysis Reveals Diversification of Enzyme Families and Niche Specialization in Globally Abundant SAR202 Bacteria. mBio. 2020;11:e02975-19.

18. Sewell HL, Kaster AK, Spormann AM. Homoacetogenesis in Deep-Sea Chloroflexi, as Inferred by Single-Cell Genomics, Provides a Link to Reductive Dehalogenation in Terrestrial Dehalococcoidetes. mBio. 2017;8:e02022-17.

19. Jamieson AJ. The hadal zone: life in the deepest oceans. Cambridge: Cambridge University Press; 2015.

20. Ichino MC, Clark MR, Drazen JC, Jamieson A, Jones DOB, Martin AP, et al. The distribution of benthic biomass in hadal trenches: A modelling approach to investigate the effect of vertical and lateral organic matter transport to the seafloor. Deep Sea Res Part I Oceanogr Res Pap. 2015;100:21-33.

21. Liu R, Wang L, Wei Y, Fang J. The hadal biosphere: Recent insights and new directions. Deep Sea Res Part II Top Stud Oceanogr. 2018;155:11-8.

22. Ikehara K, Usami K, Kanamatsu T. Repeated occurrence of surface-sediment remobilization along the landward slope of the Japan Trench by great earthquakes. Earth Planets Space. 2020;72:1-9.

23. Glud RN, Wenzhofer F, Middelboe M, Oguri K, Turnewitsch R, Canfield DE, et al. High rates of microbial carbon turnover in sediments in the deepest oceanic trench on Earth. Nat Geosci. 2013;6:284-8.

24. Wenzhöfer F, Oguri K, Middelboe M, Turnewitsch R, Toyofuku T, Kitazato H, et al. Benthic carbon mineralization in hadal trenches: assessment by in situ 02 microprofile measurements. Deep Sea Res Part I Oceanogr Res Pap. 2016;116:276-86.

25. Luo M, Glud RN, Pan B, Wenzhöfer F, Xu Y, Lin G, et al. Benthic carbon mineralization in hadal trenches: Insights from in-situ determination of benthic oxygen consumption. Geophys Res Lett. 2018;45:2752-60. 
26. Hiraoka S, Hirai M, Matsui Y, Makabe A, Minegishi H, Tsuda M, et al. Microbial community and geochemical analyses of trans-trench sediments for understanding the roles of hadal environments. ISME J. 2020;14:740-56.

27. Liu R, Wang Z, Wang L, Li Z, Fang J, Wei X, et al. Bulk and Active Sediment Prokaryotic Communities in the Mariana and Mussau Trenches. Front Microbiol. 2020;11:1521.

28. Wei ZF, Li WL, Huang JM, Wang Y. Metagenomic studies of SAR202 bacteria at the full-ocean depth in the Mariana Trench. Deep Sea Res Part I Oceanogr Res Pap. 2020;165:103396.

29. Chaumeil PA, Mussig AJ, Hugenholtz P, Parks DH. GTDB-Tk: a toolkit to classify genomes with the Genome Taxonomy Database. Bioinformatics. 2019;36:1925-7.

30. Parks DH, Chuvochina M, Chaumeil PA, Rinke C, Mussig AJ, Hugenholtz P. A complete domain-tospecies taxonomy for Bacteria and Archaea. Nat Biotechnol. 2020;38:1079-86.

31. Murray AE, Freudenstein J, Gribaldo S, Hatzenpichler R, Hugenholtz P, Kämpfer P, et al. Roadmap for naming uncultivated Archaea and Bacteria. Nat Microbiol. 2020;5:987-94.

32. Peoples LM, Grammatopoulou E, Pombrol M, Xu X, Osuntokun O, Blanton J, et al. Microbial Community Diversity Within Sediments from Two Geographically Separated Hadal Trenches. Front Microbiol. 2019;10:347.

33. Ellis HR. Mechanism for sulfur acquisition by the alkanesulfonate monooxygenase system. Bioorg Chem. 2011;39:178-84.

34. Fatayer S, Coppola Al, Schulz F, Walker BD, Broek TA, Meyer G, et al. Direct visualization of individual aromatic compound structures in low molecular weight marine dissolved organic carbon. Geophys Res Lett. 2018;45:5590-8.

35. Ang TF, Maiangwa J, Salleh AB, Normi YM, Leow TC. Dehalogenases: From Improved Performance to Potential Microbial Dehalogenation Applications. Molecules. 2018;23:1100.

36. Atashgahi S, Häggblom MM, Smidt H. Organohalide respiration in pristine environments: implications for the natural halogen cycle. Environ Microbiol. 2018;20:934-48.

37. Futagami T, Morono Y, Terada T, Kaksonen AH, Inagaki F. Distribution of dehalogenation activity in subseafloor sediments of the Nankai Trough subduction zone. Philos Trans R Soc Lond Ser B Biol Sci. 2013;368:20120249.

38. Yang Y, Sanford R, Yan J, Chen G, Cápiro NL, Li X, et al. Roles of Organohalide-Respiring Dehalococcoidia in Carbon Cycling. mSystems. 2020;5:e00757-19.

39. Vuillemin A, Kerrigan Z, D'Hondt S, Orsi WD. Exploring the abundance, metabolic potential and gene expression of subseafloor Chloroflexi in million-year-old oxic and anoxic abyssal clay. FEMS Microbiol Ecol. 2020;96:fiaa223.

40. Hagen PE, Walls MP. The Stockholm Convention on persistent organic pollutants. Nat Res Environ. 2005;19:49-52.

41. Barrett J, Chase Z, Zhang J, Holl MMB, Willis K, Williams A, et al. Microplastic Pollution in Deep-Sea Sediments From the Great Australian Bight. Front Mar Sci. 2020;7:576170. 
42. Koenig S, Huertas D, Fernández P. Legacy and emergent persistent organic pollutants (POPs) in NW Mediterranean deep-sea organisms. Sci Total Environ. 2013;443:358-66.

43. Cui J, Yu Z, Mi M, He L, Sha Z, Yao P, et al. Occurrence of Halogenated Organic Pollutants in Hadal Trenches of the Western Pacific Ocean. Environ Sci Technol. 2020;54:15821-8.

44. Jamieson AJ, Malkocs T, Piertney SB, Fujii T, Zhang Z. Bioaccumulation of persistent organic pollutants in the deepest ocean fauna. Nat Ecol Evol. 2017;1:51.

45. Liu M, Xiao W, Zhang Q, Shi L, Wang X, Xu Y. Methylmercury bioaccumulation in deepest ocean fauna: implications for ocean mercury biotransport through food webs. Environ Sci Technol Lett. 2020;7:469-76.

46. Peng G, Bellerby R, Zhang F, Sun X, Li D. The ocean's ultimate trashcan: Hadal trenches as major depositories for plastic pollution. Water Res. 2020;168:115121.

47. Simoneit BR. Hydrothermal petroleum. In: Wilkes $\mathrm{H}$, editor. Hydrocarbons, oils and lipids: diversity, origin, chemistry and fate. Springer; 2018. p. 1-35.

48. Wang W, Li Z, Zeng L, Dong C, Shao Z. The oxidation of hydrocarbons by diverse heterotrophic and mixotrophic bacteria that inhabit deep-sea hydrothermal ecosystems. ISME J. 2020;14:1994-2006.

49. Leri AC, Mayer LM, Thornton KR, Northrup PA, Dunigan MR, Ness KJ, et al. A marine sink for chlorine in natural organic matter. Nat Geosci. 2015;8:620-4.

50. Sebastián M, Estrany M, Ruiz-González C, Forn I, Sala MM, Gasol JM, et al. High Growth Potential of Long-Term Starved Deep Ocean Opportunistic Heterotrophic Bacteria. Front Microbiol. 2019;10:760.

51. Vanaporn M, Titball RW. Trehalose and bacterial virulence. Virulence. 2020;11:1192-202.

52. Dahl C, Prange A. Bacterial sulfur globules: occurrence, structure and metabolism. In: Shively JM, editor. Inclusions in Prokaryotes. Springer; 2006. p. 21-.

53. Achbergerová L, Nahálka J. Polyphosphate-an ancient energy source and active metabolic regulator. Microb Cell Fact. 2011;10:63.

54. Sauer U, Eikmanns BJ. The PEP-pyruvate-oxaloacetate node as the switch point for carbon flux distribution in bacteria. FEMS Microbiol Rev. 2005;29:765-94.

55. Yokoyama K, Ishijima SA, Clowney L, Koike H, Aramaki H, Tanaka C, et al. Feast/famine regulatory proteins (FFRPs): Escherichia coli Lrp, AsnC and related archaeal transcription factors. FEMS Microbiol Rev. 2006;30:89-108.

56. Kroner GM, Wolfe MB, Freddolino PL. Escherichia coli Lrp Regulates One-Third of the Genome via Direct, Cooperative, and Indirect Routes. J Bacteriol. 2019;201:e00411-18.

57. Liu R, Wang L, Liu Q, Wang Z, Li Z, Fang J, et al. Depth-Resolved Distribution of Particle-Attached and Free-Living Bacterial Communities in the Water Column of the New Britain Trench. Front Microbiol. 2018;9:625.

58. Bolger AM, Lohse M, Usadel B. Trimmomatic: a flexible trimmer for Illumina sequence data. Bioinformatics. 2014;30:2114-20. 
59. Peng Y, Leung HC, Yiu SM, Chin FY. IDBA-UD: a de novo assembler for single-cell and metagenomic sequencing data with highly uneven depth. Bioinformatics. 2012;28:1420-8.

60. Langmead B, Salzberg SL. Fast gapped-read alignment with Bowtie 2. Nat Methods. 2012;9:357-9.

61. Kang DD, Froula J, Egan R, Wang Z. MetaBAT, an efficient tool for accurately reconstructing single genomes from complex microbial communities. PeerJ. 2015;3:e1165.

62. Alneberg J, Bjarnason BS, de Bruijn I, Schirmer M, Quick J, ljaz UZ, et al. Binning metagenomic contigs by coverage and composition. Nat Methods. 2014;11:1144-6.

63. Song WZ, Thomas T. Binning_refiner: improving genome bins through the combination of different binning programs. Bioinformatics. 2017;33:1873-5.

64. Parks DH, Imelfort M, Skennerton CT, Hugenholtz P, Tyson GW. CheckM: assessing the quality of microbial genomes recovered from isolates, single cells, and metagenomes. Genome Res. 2015;25:1043-55.

65. Olm MR, Brown CT, Brooks B, Banfield JF. dRep: a tool for fast and accurate genomic comparisons that enables improved genome recovery from metagenomes through de-replication. ISME J. 2017;11:2864-8.

66. Eddy SR. A new generation of homology search tools based on probabilistic inference. Genome Inform. 2009;23:205-11.

67. Katoh K, Standley DM. MAFFT multiple sequence alignment software version 7: improvements in performance and usability. Mol Biol Evol. 2013;30:772-80.

68. Price MN, Dehal PS, Arkin AP. FastTree 2-approximately maximum-likelihood trees for large alignments. PLoS One. 2010;5:e9490.

69. Letunic I, Bork P. Interactive tree of life (iTOL) v3: an online tool for the display and annotation of phylogenetic and other trees. Nucleic Acids Res. 2016;44:W242-5.

70. Jain C, Rodriguez-R LM, Phillippy AM, Konstantinidis KT, Aluru S. High throughput ANI analysis of 90K prokaryotic genomes reveals clear species boundaries. Nat Commun. 2018;9:5114.

71. Camacho C, Coulouris G, Avagyan V, Ma N, Papadopoulos J, Bealer K, et al. BLAST+: architecture and applications. BMC Bioinformatics. 2009;10:421.

72. Hyatt D, Chen GL, Locascio PF, Land ML, Larimer FW, Hauser LJ. Prodigal: prokaryotic gene recognition and translation initiation site identification. BMC Bioinformatics. 2010;11:119.

73. Kanehisa M, Sato Y, Morishima K. BlastKOALA and GhostKOALA: KEGG Tools for Functional Characterization of Genome and Metagenome Sequences. J Mol Biol. 2016;428:726-31.

74. Tatusov RL, Fedorova ND, Jackson JD, Jacobs AR, Kiryutin B, Koonin EV, et al. The COG database: an updated version includes eukaryotes. BMC Bioinformatics. 2003;4:41.

75. Seemann T. Prokka: rapid prokaryotic genome annotation. Bioinformatics. 2014;30:2068-9.

76. Yin Y, Mao X, Yang J, Chen X, Mao F, Xu Y. dbCAN: a web resource for automated carbohydrate-active enzyme annotation. Nucleic Acids Res. 2012;40:445-. 


\section{Figures}
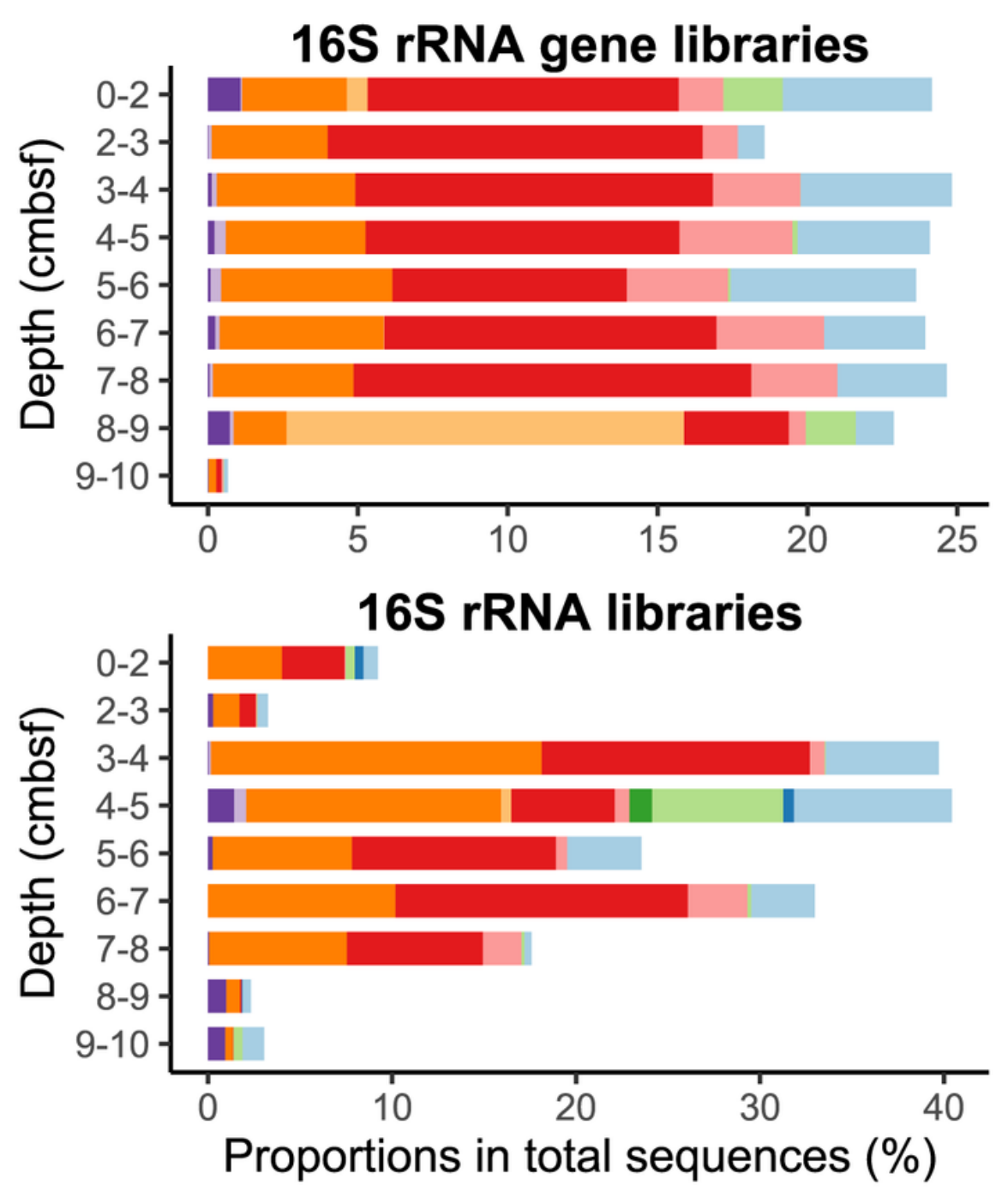

\section{Class Anaerolineae} Anaerolineales

RBG-13-54-9 SBR1031

unclassified Anaerolineae Class Dehalococcoidia S085 SAR202 clade Class Chloroflexia Chloroflexales Class JG30-KF-CM66 norank JG30-KF-CM66 Class KD4-96 norank KD4-96 others

\section{Figure 1}

Composition of the potentially active (A) and bulk (B) Chloroflexi in the hadal sediments at class level, revealed by $16 \mathrm{~S}$ rRNA and $16 \mathrm{~S}$ rRNA gene. 


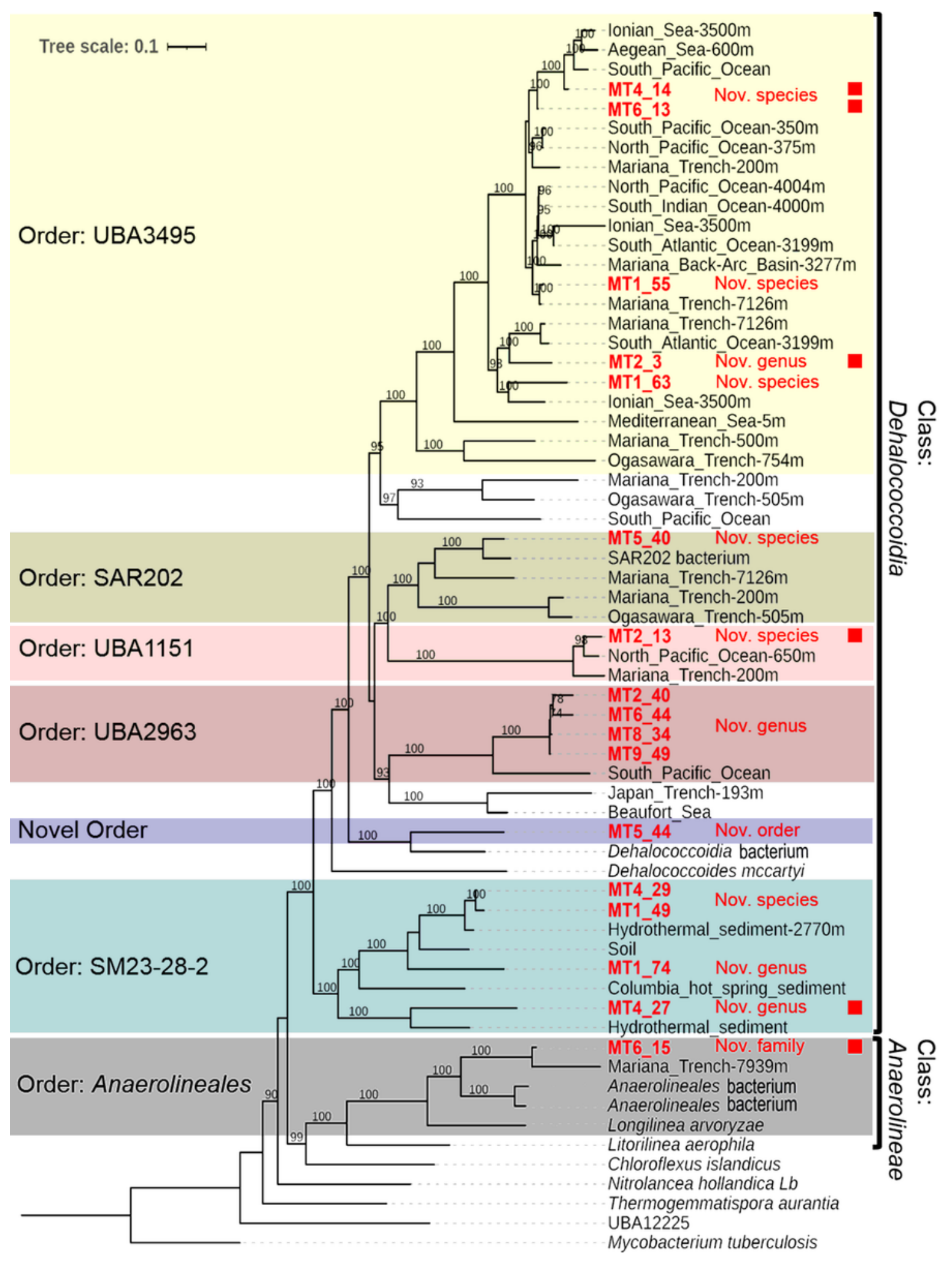

Figure 2

Maximum likelihood phylogenomic tree of the 17 selected Chloroflexi MAGs. Genome of Mycobacterium tuberculosis was used as the root. Bootstrap values were calculated based on 100 replicates and the values higher than $90 \%$ were indicated at the base of corresponding node. The colored backgrounds show the genomes belonging to the same order. The taxonomy was determined using GTDB-tk and the novelty of the recovered genomes were determined based on GTDB classification and ANI values 
between the MAGs and their closest genomes in GTDB and NCBI databases. Red square indicates the MAGs with completeness $>80 \%$.

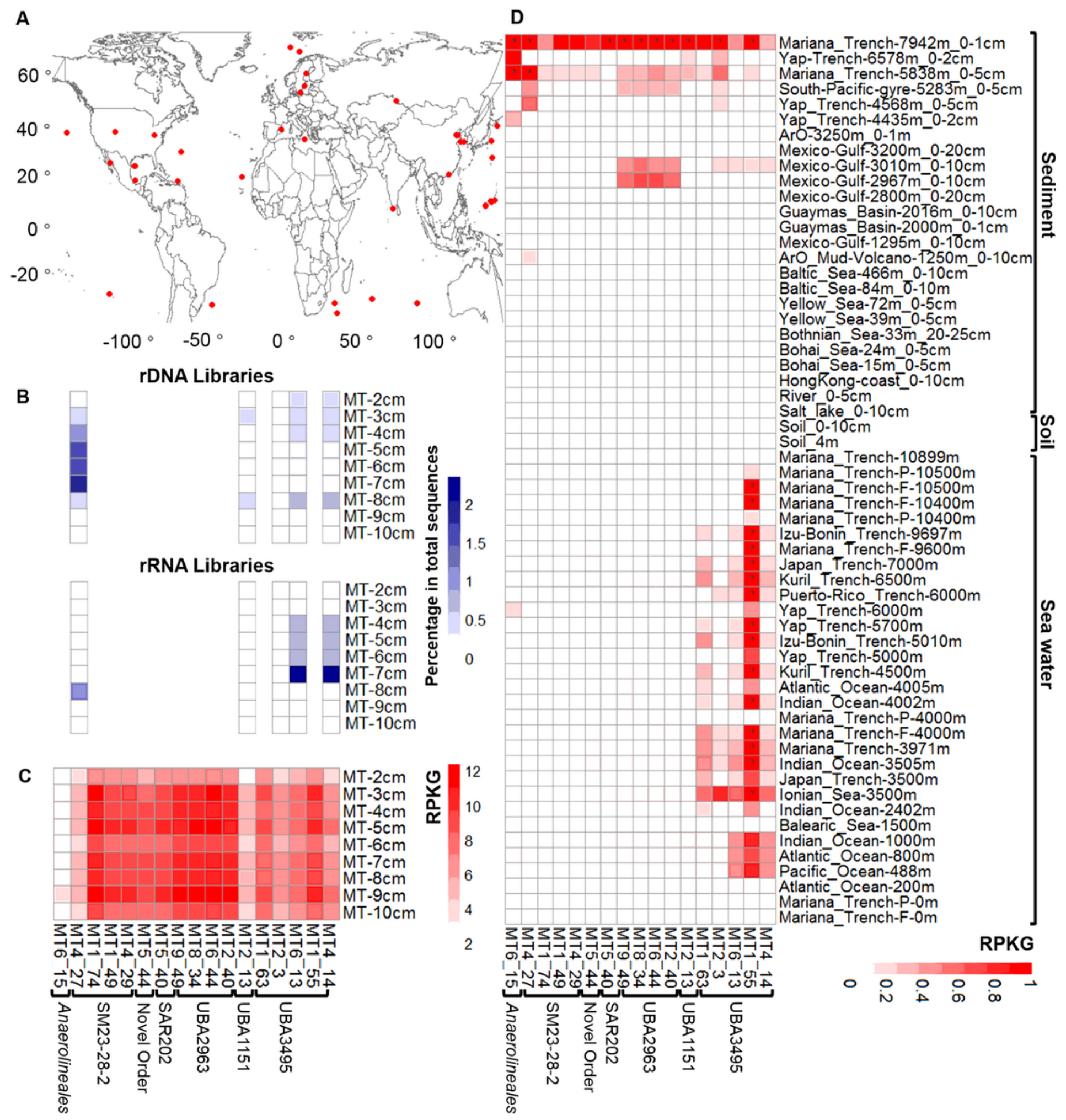

\section{Figure 3}

Distribution of the recovered MAGs in hadal sediments and other natural ecosystems. (A) The sampling sites of the datasets included in the analysis; (B) the relative abundance of the closest matched OTUs in 16S rRNA and 16S rRNA gene libraries of sediments of the Challenger Deep. The MAGs without any value 
in 16S rRNA or 16S rRNA gene libraries means no matched OTUs due to lacking of 16S rRNA gene in the corresponding MAG; $(C)$ the read recruitment of recovered MAGs in metagenomes from different layers of hadal sediments of the Challenger Deep; and (D) read recruitments in other natural ecosystems. The name of samples from sediments were shown as "sampling site (region)_water depth of the site_depth below seafloor". The black dots in the heatmap boxes are indicating outlier values. Note: The designations employed and the presentation of the material on this map do not imply the expression of any opinion whatsoever on the part of Research Square concerning the legal status of any country, territory, city or area or of its authorities, or concerning the delimitation of its frontiers or boundaries. This map has been provided by the authors.

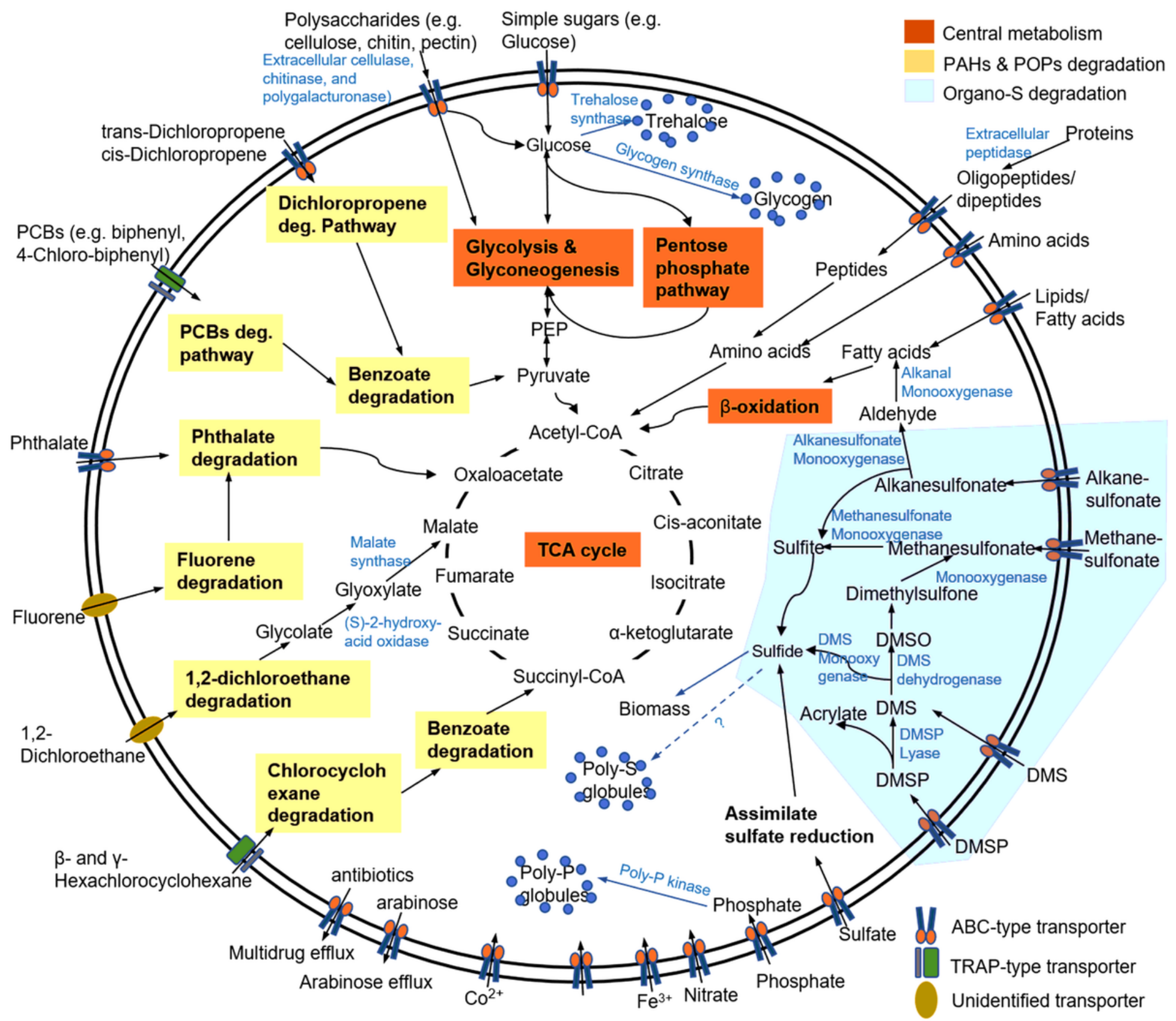

Figure 4 
Overview of the metabolic potentials in assembled Chloroflexi MAGs. Black arrows show the annotated metabolic pathways and the linkage between different metabolic flows. The pathways with light blue background show the degradation pathways of organosulfur compounds, and those with yellow background show the degradation of different recalcitrant compounds.

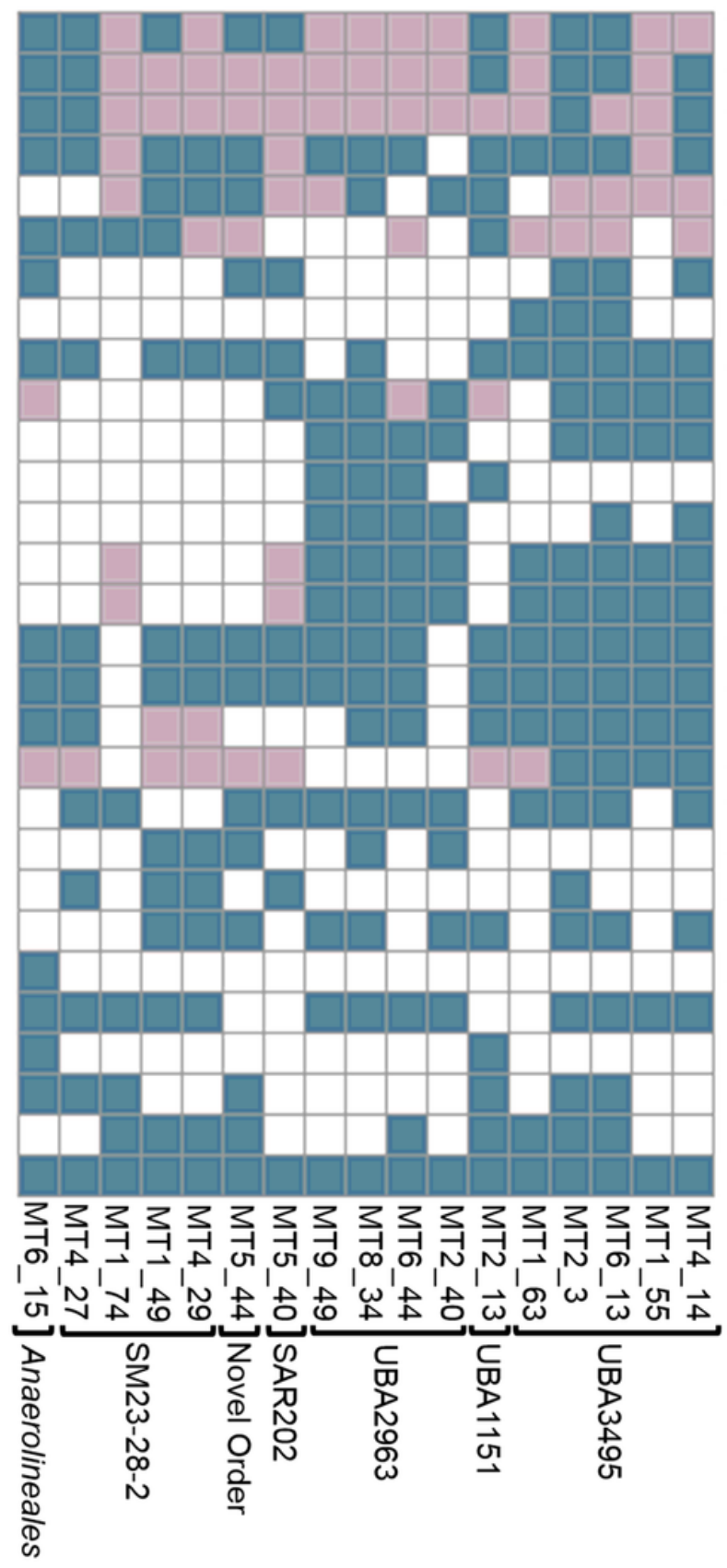

TCA cycle

Clycolysis

Cluconeogenesis

Pentose phosphate pathway

Assimilatory sulfate reduction

B-Oxidation

DMSP/DMS deg. (DMSP $\rightarrow$ Methanesulfonate)

Methanesulfonate deg. (Methanesulfonate $\rightarrow$ Sulfite)

Alkanesulfonate deg. (Alkanesulfonate $\rightarrow$ Fatty acids)

Benzoate deg. (Benzoate $\rightarrow$ Pyruvate)

Phthalate deg.-1 (Phthalate $\rightarrow$ HCMS)

Phthalate deg.-2 (HCMS $\rightarrow$ Pyruvate)

Fluorene deg. (Fluorene $\rightarrow$ Phthalate)

Biphenyl deg. (Biphenyl $\rightarrow$ Benzoate)

4-Chlorobiphenyl deg. (4-Chlorobiphenyl $\rightarrow$ 4-Hydroxybenzoyl-CoA)

Trans-Dichloropropene deg. (Trans-1,3-Dichloropropene $\rightarrow$ CAA)

Cis-Dichloropropene deg. (Cis-1,3-Dichloropropene $\rightarrow$ Cis-CAA)

1,2-Dichloroethane deg. (1,2-Dichloroethane $\rightarrow$ Glycolate)

y-Hexachlorocyclohexane ( $y$-Hexachlorocyclohexane $\rightarrow$ Succinyl-CoA) ..

Trehalose synthase (Trehalose formation)

Glycogen synthase (Glycogen formation)

Sulfide-quinone reductase (Ploy-S formation )

Sulfite reductase (Ploy-S formation )

Sulfide dehydrogenase (Ploy-S formation )

Pyruvate, orthophosphate dikinase

Phosphoenolpyruvate carboxylase

Malate dehydrogenase

NAD-dependent malic enzyme

DNA-binding transcriptional regulator, Lrp family
$\downarrow$ Central metabolism
Organosulfur metabolism
Intracellular inclusions
$\downarrow$ Aromatic compounds and $\mathrm{PAH}$ deg.
\. Metabolism regulation
Polychlorobiphenyl(PCB) deg.
$\downarrow$ Organohalide deg. (Chloroalkenes and Chlorocyclohexane)
$\square$ Absent $\square$ Partial $\square$ Complete or near complete

\section{Figure 5}

Presence and completeness of the metabolic pathways identified in the Chloroflexi MAGs. "Complete or near complete" indicates pathways that were complete or with one enzyme missing, "partial" indicates pathways that were with two or more enzymes missing, and "absent" means none of the enzymes in the pathways were identified. 
A

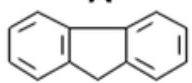

Fluorene

Naphthalene 1,2dioxygenase<smiles>OC1c2ccccc2-c2ccccc21</smiles>

Fluoren-9-ol

|Fluoren-9-ol dehydrogenase<smiles>O=C1c2ccccc2-c2ccccc21</smiles>

Fluoren-9-one

Dibenzofuran dioxygenase<smiles>O=C1c2ccccc2C2=CC=C[C@H](O)[C@@]12O</smiles>

1-Hydro-1,1adihydroxy-9-

fluorenone

| Fluoren-9-ol

dehydrogenase

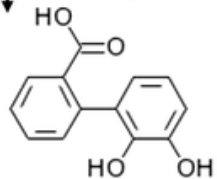

2,3-Dihydroxy-2'carboxybiphenyl

2'-carboxy-2,3dihydroxybiphenyl

1,2-dioxygenase<smiles>O=C(O)/C(O)=C\C=C/C(=O)c1ccccc1C(=O)O</smiles>

2-Hydroxy-6-oxo-6hexa-2,4-dienoate 2-hydroxy-6-oxo-6(2'-carboxyphenyl)hexa-2,4-dienoate hydrolase<smiles>O=C(O)c1ccccc1C(=O)O</smiles>

Phthalate

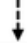

Phthalate degradation
B

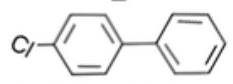

4-Chlorobiphenyl

Biphenyl 2,3-

dioxygenase

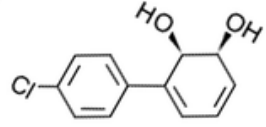

Cis-2,3-Dihydro-2,3Dihydroxy-4'chlorobiphenyl

Cis-2,3-

dihydrobiphenyl-2,3-

diol dehydrogenase

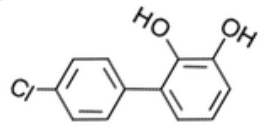

4'-Chloro-2,3-biphenyldiol

| Biphenyl-2,3-diol

1,2-dioxygenase

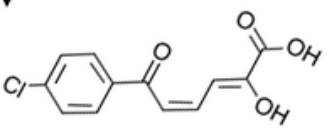

2-Hydroxy-6-oxo-6-

(4'-chlorophenyl)-

hexa-2,4-dienoate

2,6-dioxo-6-

phenylhexa-3-enoate

hydrolase

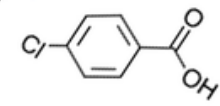

\section{4-Chlorobenzoate}

4-chlorobenzoate-

CoA ligase

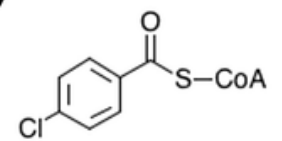

4-Chlorobenzoyl-CoA

4-chlorobenzoyl-

CoA dehalogenase

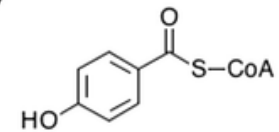

4-Hydroxybenzoyl-CoA

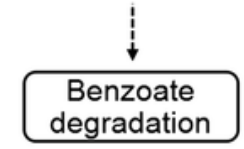<smiles>C[C@H]1C(Cl)[C@H](Cl)[C@H](Cl)C(Cl)[C@H]1Cl</smiles>

$\mathrm{y}$-Hexachlorocyclohexane

y-Hexachloro-

cyclohexane

dehydrochlorinase

Cl

Y-Pentachloro-

cyclohexene

Y-hexachloro-

cyclohexane

dehydrochlorinase<smiles>ClC1=CC(Cl)C(Cl)=CC1Cl</smiles>

1,3,4,6-Tetrachloro-

1,4-cyclohexadiene

Haloalkane

dehalogenase<smiles>O[C@H]1C=C(Cl)[C-](Cl)C=C1Cl</smiles>

2,4,5-Trichloro-2,5cyclohexadiene-1-ol

Haloalkane

dehalogenase<smiles>O[C@H]1C=C(Cl)C(Cl)=C[C@H]1O</smiles>

2,5-Dichloro-2,5cyclohexadiene-1,4-diol

2,5-dichloro-2,5cyclohexadiene-1,4diol dehydrogenase<smiles>Oc1cc(Cl)c(O)cc1Cl</smiles>

2,5-Dichlorohydroquinone

| Chlorophenol-4-

monooxygenase and

Flavin reductase<smiles>O=C1C=C(O)C(=O)C=C1O</smiles>

5-Chloro-2hydroxy-pbenzoquinone

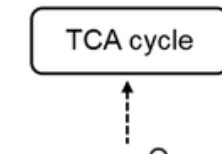<smiles>O=C(O)CCC(=O)SC(=O)O</smiles>

Succinyl-CoA

$\uparrow$ Acetyl-CoA<smiles>O=C(O)CCC(=O)CC(=O)SC(=O)O</smiles>

3-Oxoadipyl-CoA

$\uparrow$ 3-oxoadipate

CoA-transferase<smiles>O=C(O)CCC(=O)CC(=O)O</smiles>

3-Oxoadipate

Maleylacetate

reductase<smiles>O=C(O)CC(=O)CC(=O)O</smiles>

Maleylacetate

$\uparrow$ Hydroxyquinol

1,2-dioxygenase<smiles>Oc1ccc(O)c(O)c1</smiles>

Benzene-1,2,4-triol

2-hydroxy-1,4benzoquinone reductase<smiles>O=C1C=CC(=O)C(O)=C1</smiles>

2-Hydroxy-1,4benzoquinone

$\uparrow$ y-hexachlorocyclohexane dehydrochlorinase<smiles>COc1cc(OC)c(O)cc1O</smiles>

5-Chloro-1,2,4trihydroxybenzene

Figure 6

The degradation pathways of representative PAHs and POPs identified in hadal sedimentary Chloroflexi MAGs. These pathways were potentially utilized for complete degradation of (A) Fluorene, (B) 4chlorobiphenyl, (C) 1,2-Dichloroethane, and (D) $y$-Hexachlorocyclohexane. The illustrated pathways were found to be complete in at least one MAG recovered in this study. 
Feast condition

\begin{tabular}{|l}
\hline Labile OM \\
(e.g. simple sugars, \\
fatty acids, amino acids)
\end{tabular}

Famine condition

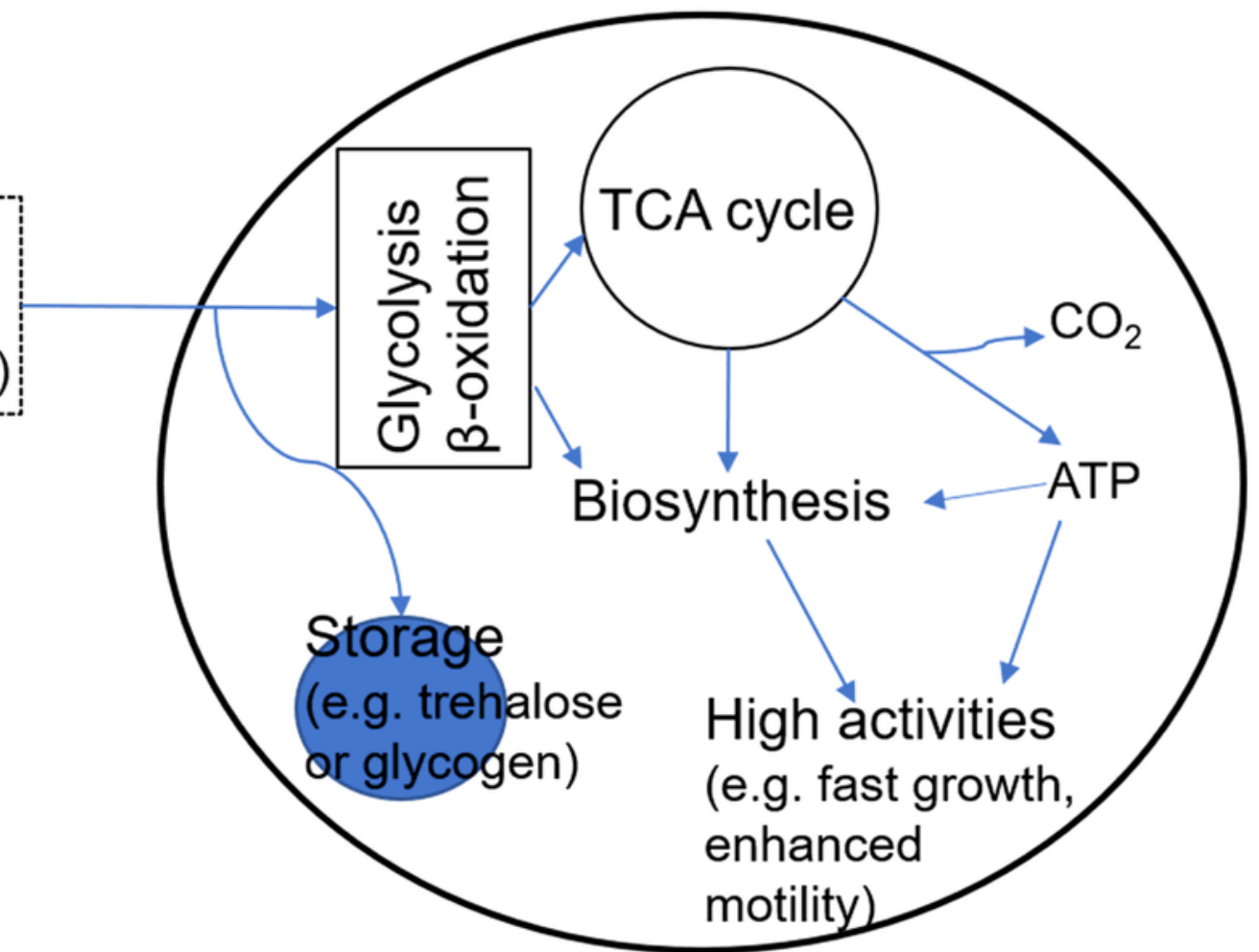

Complex OC

(e.g. cellulose, chitin)

Organosulfur

(e.g. alkanesulfonate)

Recalcitrant OM

(e.g. aromatics, PAHs, organohalids)

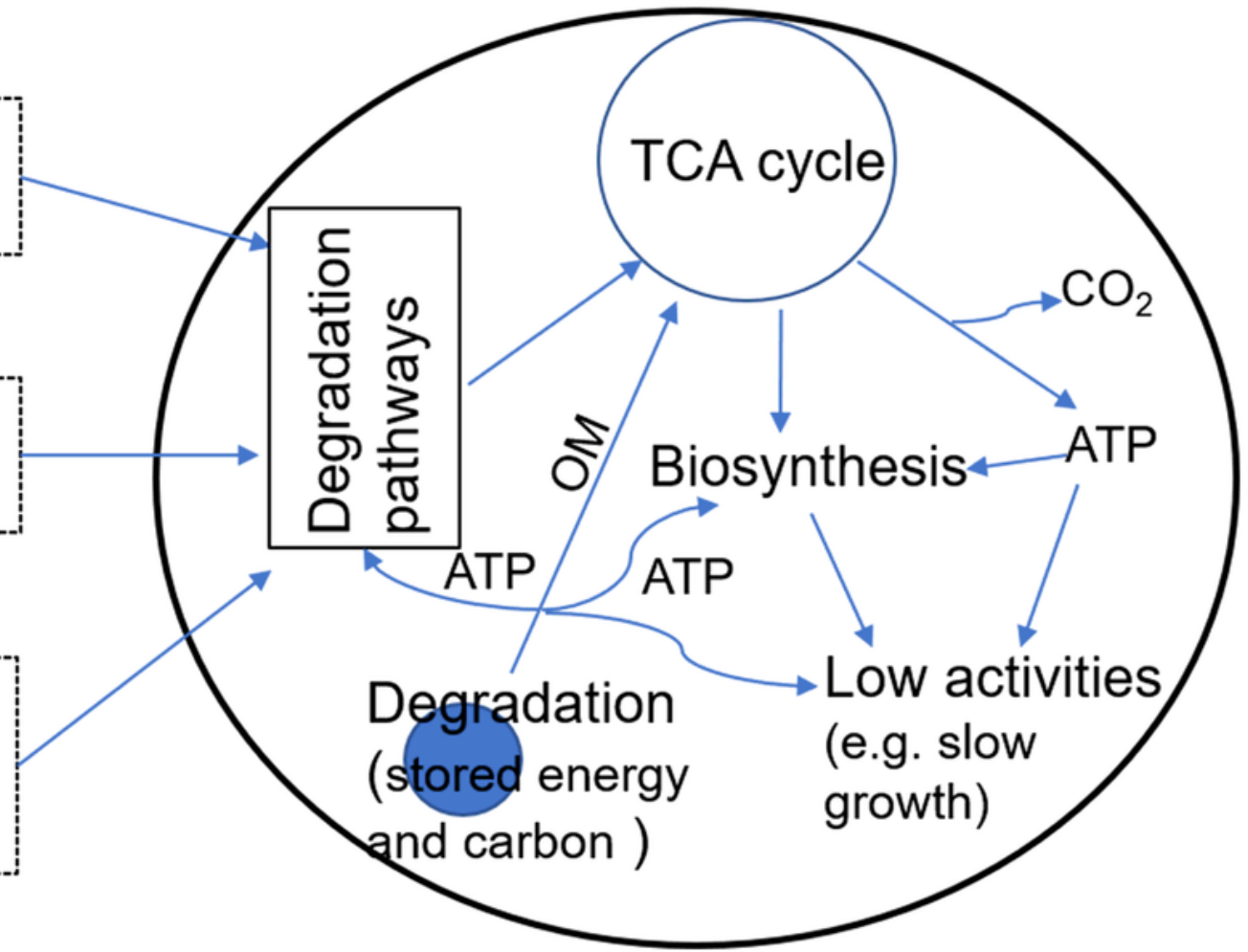

Figure 7

A proposed "feast and famine" metabolic strategy of hadal sediment Chloroflexi recovered in this study.

\section{Supplementary Files}

This is a list of supplementary files associated with this preprint. Click to download. 
- Additionalfile1supportingtablesfinal.xIsx

- Additionalfile2supportingfiguresfinal.docx

- Additionalfile3taxonomynames.docx 